\title{
ZCS-PWM Converter for Reducing Switching Losses
}

\author{
Subi S. \\ M-Tech Power and Energy, Guest Lecturer at College of Engineering Trivandrum,Kerala.
}

\begin{abstract}
Zero-current (ZC) switching pulse-width modulated (PWM) fly back DC-DC converter is an extended version of the single switch fly back converter with an auxiliary circuit. The main switch and auxiliary switch operate at ZCS turn-on and turn-off conditions, and all uncontrolled devices in the converter operate at zero-voltage-switching (ZVS) turn-on and turn-off. Soft switching techniques are used in PWM DC-DC converters to reduce switching losses and electromagnetic interference (EMI). The circulating current for the soft switching flows only through the auxiliary circuit, the conduction loss and current stress of the main switch are minimized. The general principle of operation of ZCS flyback converter, its merits and demerits, experimental setup and results has been summarized.

Keywords: Flyback converter, Auxillary circuit, zero current switching(zcs),experimental setup and results.
\end{abstract}

\section{Introduction}

A typical DC-DC converter is comprised of active switches such as MOSFETs or IGBTs, diodes, magnetic components such as inductors and transformers, and static devices such as capacitors. Magnetic components are heavier and occupy more volume than any other parts in a power electronic converter. The size of the magnetic components is inversely proportional to the switching frequency of the converter. In order to decrease the volume and weight of a DC-DC converter, higher switching frequency must be chosen. Increasing the switching frequency leads to increased switching losses which in turn reduces the converter efficiency. Soft switching techniques are used in PWM DC-DC converters to reduce switching losses and electromagnetic interference (EMI).

The pulse width modulation (PWM) technique is highly regarded for its high power capability, fast transient response and ease of control. PWM dc-dc converters have been widely used in industry. Among these $\mathrm{dc} / \mathrm{dc}$ converters, the flyback topology is the most attractive because of its relative simplicity compared with other topologies used in low power applications. The flyback transformer serves the dual purpose of providing energy storage as well as converter isolation, theoretically minimizing the magnetic component count when compared with the forward converter. Flyback converters are isolated versions of buck-boost converters and are widely used in low to medium power applications. They are relatively simple and have very few components.

The paper discusses about a novel ZCS-PWM flyback converter with a simple ZCS-PWM auxiliary circuit. All semiconductor devices are operated at ZCS turn-on and turn-off condition. It does not require a floating and an isolated driver for the auxiliary switch to decrease the complexity of the control circuit, since the two switches have a common ground. Since the circulating current for soft switching flows only through the auxiliary circuit, the conduction loss and current stress of the main switch are minimized. In addition, at constant frequency and with reduced commutation losses, the new ZCS-PWM flyback converter has no additional current stress and conduction losses in the main switch compared to its hard switching flyback converter counterpart.

\section{Zcs-Pwm Flyback Converter}

The block diagram for the converter is shown in fig.1. Here the first block represents the input dc power supply which is $100 \mathrm{~V}$. The supply is provided to the flyback converter shown in fig. 2 . The control to the converter is provided through the control circuit. The converter provides an output de voltage of $12 \mathrm{~V}$.

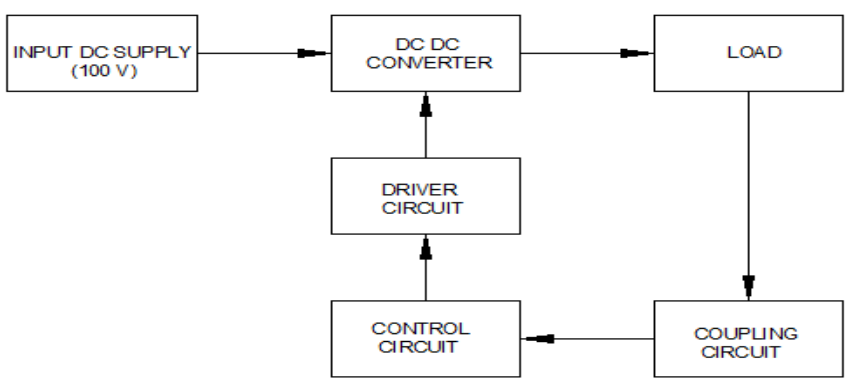

Fig. 1 Block diagram for zcs-pwm converter 


\section{A. Circuit Description}

The circuit for the converter is shown in fig. 2. The circuit consists of two sections. The first part is the conventional flyback converter, which consists of an isolated transformer, switch Sm, diode $\mathrm{D}_{1}$ and the output filter $\mathrm{C}_{0}$. The second part consists of an auxiliary circuit to provide ZCS on the switch Sm. This consists of auxiliary diodes $\mathrm{D}_{2}, \mathrm{D}_{3}$, the resonant inductor $\mathrm{Lr}$, the resonant capacitor $\mathrm{Cr}$ and the auxiliary switch Sa.

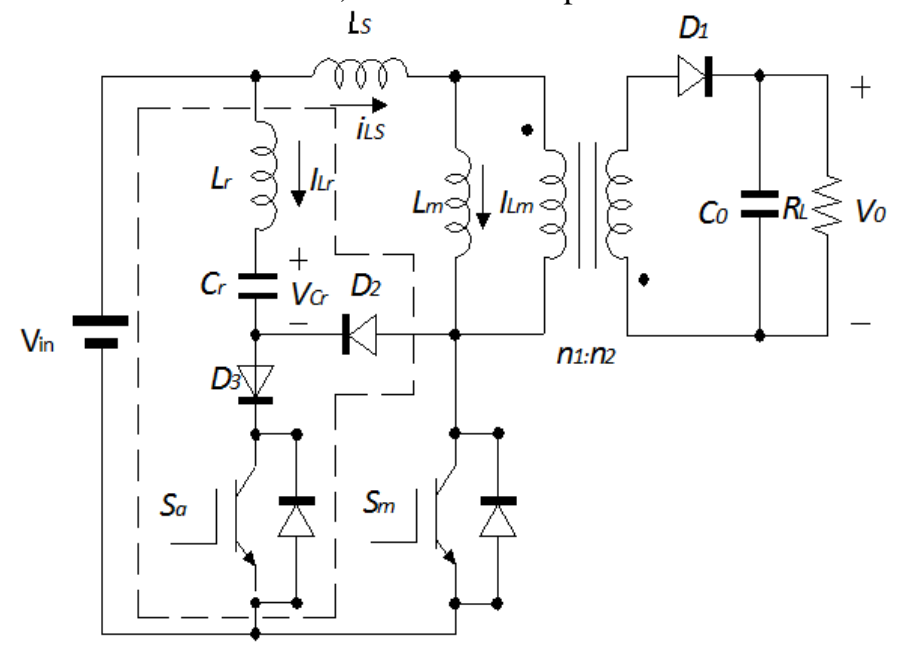

Fig. 2 ZCS-PWM flyback converter

\section{a. Principle of Operation}

The operation for the converter system is explained as follows:

When the main switch $S_{m}$ is on, $L_{m}$ and $L_{s}$ are charged by the input voltage source and the converter operation is same as that of a conventional hard-switched flyback converter. The auxiliary switch $S_{a}$ is turned on just before $S_{m}$ is turned off resulting in resonance betwe en $L_{r}$ and $C_{r}$. The resonant capacitor $C_{r}$ is discharged by the resonant current in the auxiliary circuit. When the resonant current reaches zero, the diode $D_{2}$ seizes conduction and stops the flow of resonant current through $S_{a}$. The resonant current now flows through $D_{1}$ and charges $C_{r}$. When the resonant current through $S_{m}$ reverses, the antiparallel diode $D_{m}$ begins to conduct. When the diode $D_{m}$ seizes conduction, the current through $S_{m}$ is zero thereby creating a ZCS condition for $S_{m}$ and $S_{a}$. The switches $S_{m}$ and $S_{a}$ are turned off during this time period. When the switches are turned off, the resonance between $L_{s}, L_{r}$, and $C_{r}$ begin, and the resonant current continues to charge $C_{r}$. The output rectifier $D_{l}$ is forward biased and the magnetizing inductance current is transferred to the load. When the energy stored in $L_{r}$ and $L_{s}$ is transferred to $C_{r}$, the diode $D_{l}$ commutates all of the magnetizing inductance current to the output until $S_{m}$ is turned on in the next switching cycle.

\section{Advantages}

- All the semiconductor devices are turned on softly and turned off with ZCS condition.

- The circulating current flows only through the auxiliary circuit and hence there is no additional current stress on the main switch.

- The auxiliary switch conducts for a very small period of time resulting in reduced conduction losses due to circulating current.

- The auxiliary switch is referenced with respect to the ground making it easier to drive.

- The auxiliary switch is turned off at the same time instant as that of the main switch making the control logic simpler.

Disadvantages

- When both the switches are turned off, the parasitic output capacitance of the main switch, auxiliary switch, auxiliary diode $D_{a 1}$, and the rectifier diode $D$ participate in the resonance of $L_{l}, L_{r}$, and $C_{r}$, due to which the voltage stresses across $S_{p}, S_{a}, D_{a 2}$, and $D$ are significantly increased.

- Since the voltage across $C r$ swings from $-4 V_{l}$ to $6 V_{l}$, the stresses of $C r$ can be very large in high input voltage applications.

- The ZCS-PWM commutation cell needs an additional inductor $L_{r}$ for the resonance. Also two additional auxiliary diodes are required for proper ZCS operation. 


\section{A. Stages of operation}

Mode 1: [Fig.3(a): $t_{0}<t<t_{1}$ ]: is Before $t=t_{0}$, both switches $S_{\mathrm{m}}$ and $S_{\mathrm{a}}$ maintain turn-off state. The energy stored in magnetizing inductor $L \mathrm{~m}$ is delivered to output filter capacitor $C_{\mathrm{o}}$ and loaded through the ideal transformer and diode $D 1$. This stage started when the main switch $S_{\mathrm{m}}$ turns on with ZCS at $t=t_{0}$. The leakage inductor $L_{\mathrm{s}}$ charges linearly to output voltage $V \mathrm{o}$ from zero to $I_{\mathrm{Lm}}$. The stage ends when the current in the leakage inductor $L$ s reaches $I_{\mathrm{Lm}}$ and diode $D_{1}$ turns off with ZCS at $t=t 1$. The resonant current $i \operatorname{Lr}(t)$, resonant voltages $V_{\mathrm{Cr}(t),}$ and the current $i_{\mathrm{Ls}(t)}$ in leakage inductor can be described as

$$
\begin{aligned}
& \mathrm{i}_{\mathrm{Lr}}(\mathrm{t})=0 \\
& \mathrm{i}_{\mathrm{Ls}}(\mathrm{t})=\left(\mathrm{V}_{\text {in }}+\mathrm{nV}_{0}\right)\left(\mathrm{t}-\mathrm{t}_{0}\right) \\
& \mathrm{V}_{\mathrm{Cr}}(\mathrm{t})=\mathrm{V}_{\mathrm{Cr} 0} \\
& \Delta \mathrm{t}_{1}=\mathrm{I}_{\mathrm{Lm}} \mathrm{L}_{\mathrm{s}} / \mathrm{V}_{\text {in }}+\mathrm{nV}_{0}
\end{aligned}
$$

Mode 2 [Fig.3(b): $t_{1}<t<t_{2}$ ]: When the current $i \mathrm{Ls}(t)$ in leakage inductor $L$ s reaches $I \mathrm{Lm}$ and diode $D 1$ turns off with ZCS at $t=t 1$, this stage is started. The magnetizing inductor $L \mathrm{~m}$ and the leakage inductor $L \mathrm{~s}$ are linearly charged by input voltage source Vin together. This operating behaviour is the same as the conventional PWM flyback dc/dc converter operating at turn-on state. The resonant current $i \operatorname{Lr}(t)$, resonant voltages $V_{\mathrm{Cr}(t) \text {, and the }}$ current $i_{\mathrm{LS}(t)}$ in leakage inductor can be described as

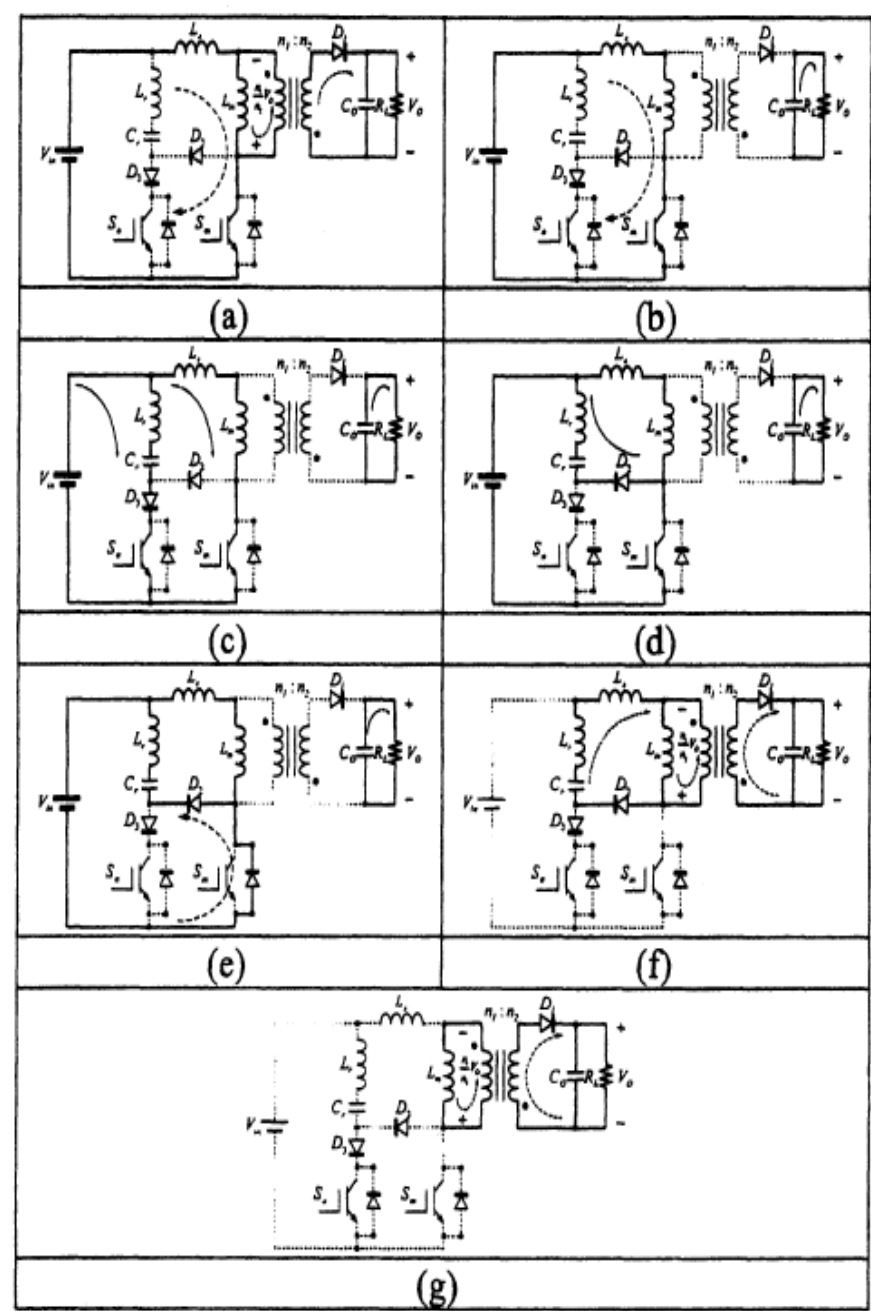

Fig. 3 Seven dynamic equivalent circuits of converter during one switching cycle 


$$
\begin{aligned}
& \mathrm{i}_{\mathrm{Lr}}(\mathrm{t})=0 \\
& \mathrm{i}_{\mathrm{Ls}}(\mathrm{t})=\mathrm{I}_{\mathrm{Lm}} \\
& \mathrm{v}_{\mathrm{Cr}}(\mathrm{t})=\mathrm{V}_{\mathrm{Cr} 0} \\
& \Delta \mathrm{t}_{2}=\mathrm{DT}_{\mathrm{S}}-\Delta \mathrm{t}_{1}
\end{aligned}
$$

where $D$ is the duty ratio and time of the main switch at turn-on state in a conventional PWM flyback dc/dc converter, $T \mathrm{~s}=1 / f \mathrm{~s}$ is the switching period, and $f \mathrm{~s}$ is the switching frequency.

Mode 3 [Fig.3(c): $t 2<t<t 3$ ]: This stage begins when the auxiliary switch $S \mathrm{a}$ is turned on at $t=t_{2}$. Because the initial value of resonant current $i_{\mathrm{Lr}}(t)$ is zero, ZCS in auxiliary switch $S$ a can be achieved. The resonance of resonant inductor $L \mathrm{r}$ and capacitor $C \mathrm{r}$ is started by $V_{\mathrm{in}}, \mathrm{Lr}, \mathrm{Cr}, D_{3}$, and $S \mathrm{a}$. The resonant current $i_{\mathrm{Lr}}(t)$ increases and then decreases when it reaches peak value. The resonant voltage $v_{\mathrm{Cr}}(t)$ also increases. The magnetizing inductor $L \mathrm{~m}$ and the leakage inductor $L s$ are continuously charged by input voltage source $V_{\text {in }}$ together. This state ends when the resonant current $i_{\mathrm{Lr}}(t)$ drops to null again and the resonant voltage has reached its peak value. The

diode $D_{3}$ is naturally closed. The resonant current $i_{\mathrm{Lr}}(t)$, resonant voltages $v_{\mathrm{Cr}}(t)$, and the current $i_{\mathrm{Ls}}(t)$ in leakage inductor can be described as

$$
\begin{aligned}
& i_{\mathrm{Lr}}(t)=\sin \omega_{\mathrm{r}}\left(\mathrm{t}-\mathrm{t}_{2}\right) \\
& \mathrm{i}_{\mathrm{Ls}}(\mathrm{t})=\mathrm{I}_{\mathrm{Lm}} \\
& \mathrm{V}_{\mathrm{Cr}}(\mathrm{t})=\mathrm{Vin}+\left(\mathrm{V}_{\mathrm{Cr} 0}-\mathrm{V}_{\mathrm{in}}\right) \cos \omega_{\mathrm{r}}\left(\mathrm{t}-\mathrm{t}_{2}\right) \\
& \mathrm{t}_{3}=\pi / \omega \mathrm{r}
\end{aligned}
$$

where $\quad \mathrm{Z}_{0}=\sqrt{\mathrm{Lr}} / \sqrt{\mathrm{Cr}}, \omega_{\mathrm{r}}$

$$
=1 /(\sqrt{\mathrm{Lr}} \sqrt{\mathrm{Cr}})
$$

Mode 4 [Fig.3(d): $t_{3}<t<t_{4}$ ]: In this stage, the resonant behaviour in stage 3 is maintained, but the resonant route changes following $V_{\mathrm{in}}, \mathrm{Lr}, \mathrm{Cr}, D_{2}$, and $S_{\mathrm{m}}$. The resonant voltage $v_{\mathrm{Cr}}(t)$ decreases and the resonant current $i_{\mathrm{Lr}}(t)$ rises toward its negative peak value. The magnetizing inductor $L_{\mathrm{m}}$ and the leakage inductor $L_{\mathrm{s}}$ are continuously charged by input voltage source $V_{\text {in }}$ together. The stage is finished when the resonant current $i_{\mathrm{Lr}}(t)$ rises to $-I_{\mathrm{Lm}}$ at $t=t_{4}$. The resonant current $i_{\mathrm{Lr}}(t)$, resonant voltages $v_{\mathrm{Cr}}(t)$, and the current $i_{\mathrm{Ls}}(t)$ in leakage inductor can be described as

$$
\begin{aligned}
& \mathrm{i}_{\mathrm{Lr}}(\mathrm{t})=\left(\operatorname{Vin}-\mathrm{VCr}_{0}\right) / \mathrm{Z}_{0} \sin \omega_{\mathrm{r}}\left(\mathrm{t}-\mathrm{t}_{2}\right) \\
& \mathrm{i}_{\mathrm{Ls}}(\mathrm{t})=\mathrm{I}_{\mathrm{Lm}} \\
& v_{\mathrm{Cr}}(t)=V_{\text {in }}+\left(V_{\mathrm{Cr} 0}-V_{\mathrm{in}}\right) \cos \omega_{\mathrm{r}}\left(t-t_{2}\right) \\
& \Delta \mathrm{t}_{5}=(1 / \omega r) \sin ^{-1}\left(\mathrm{I}_{\mathrm{Lm}} \mathrm{Z}_{0}\right) /\left(\mathrm{V}_{\mathrm{in}}-\mathrm{V}_{\mathrm{C} 0}\right)
\end{aligned}
$$

Mode 5 [Fig.3(e): $t_{4}<t<t_{5}$ ]: At $t=t_{4}$, the resonant current $i_{\mathrm{Lr}}(t)$ rises to $-I_{\mathrm{Lm}}$ and its flow path is changed by $V_{\mathrm{in}}, L_{\mathrm{r}}, C_{\mathrm{r}}, D_{2}$, and the antiparallel diode of $S \mathrm{~m}$. Thus, no current flows through the main switch $S \mathrm{~m}$. Furthermore, because the diode $D_{3}$ is naturally closed at $t=t 3$, no current also flows through the auxiliary switch $S_{\mathrm{a}}$. It is the best time to turn off the switches $S_{\mathrm{m}}$ and $S_{\mathrm{a}}$ under ZCS. The switches $S_{\mathrm{m}}$ and $S_{\mathrm{a}}$ are simultaneously turned off at ZCS at $t=t_{4}$ and this stage is started. In this stage, the resonant operation in stage 3 is continuously maintained, while the resonant voltage $v_{\mathrm{Cr}}(t)$ continuously drops. The resonant current $i_{\mathrm{Lr}}(t)$ rises toward its negative peak value and then decreases. The magnetizing inductor $L \mathrm{~m}$ and the leakage inductor $L \mathrm{~s}$ are continuously charged by input voltage source $V_{\text {in }}$ together. When the resonant current $i_{\mathrm{Lr}}(t)$ drops to $-I_{\mathrm{Lm}}$ again, the antiparallel diode of $S \mathrm{~m}$ is naturally closed and this stage is finished. The resonant current $i \operatorname{Lr}(t)$, resonant voltages $v \operatorname{Cr}(t)$, and the current $i \mathrm{Ls}(t)$ in leakage inductor can be described as 


$$
\begin{aligned}
& \mathrm{i}_{\mathrm{Lr}}(\mathrm{t})=\left(\mathrm{Vin}-\mathrm{VCr}_{0}\right) / \mathrm{Z}_{0} \sin \omega_{\mathrm{r}}\left(\mathrm{t}-\mathrm{t}_{2}\right) \\
& \mathrm{i}_{\mathrm{Ls}}(\mathrm{t})=\mathrm{I}_{\mathrm{Lm}} \\
& v_{\mathrm{Cr}}(t)=V_{\text {in }}+\left(V_{\mathrm{Cr} 0}-V_{\text {in }}\right) \cos \omega_{\mathrm{r}}\left(t-\mathrm{t}_{2}\right) \\
& \Delta \mathrm{t}_{5}=\pi / \omega_{1}-\Delta \mathrm{t}_{4}
\end{aligned}
$$

Mode 6 [Fig.3(f): $t 5<t<t 6$ ]: During this stage, the antiparallel diode of $S_{\mathrm{m}}$ is naturally closed and the diode $D 1$ is turned on with ZCS. The energy stored in magnetizing inductor $L_{\mathrm{m}}$ begins to load through $D_{1}$ and the voltage across the primary winding is fixed in $-n V \mathrm{o}$. Thus, another resonant route is formed by $C \mathrm{r}, L \mathrm{r}, L \mathrm{~s}, n V \mathrm{o}$, and $D_{2}$. The resonant voltage $v_{\mathrm{Cr}}(t)$ continuously decreases. The resonant current $i_{\mathrm{Lr}}(t)$ rises toward zero value and the current $i_{\mathrm{Ls}}(t)$ in the leakage inductor drops toward zero value. This stage ends when the energies stored in the resonant inductor $L \mathrm{r}$ and the leakage inductor $L s$ are completely transferred to the resonant capacitor $C \mathrm{r}$. The resonant current $i \operatorname{Lr}(t)$, resonant voltages $v \operatorname{Cr}(t)$, and the current $i \operatorname{Ls}(t)$ in leakage inductor can be described as

$\mathrm{i}_{\mathrm{Lr}}(\mathrm{t})=-\mathrm{I}_{\mathrm{Lm}} \cos \omega_{\mathrm{r}} 1 /\left(\sqrt{ }\left(1+\mathrm{n}_{\mathrm{L}}\right)\right)\left(\mathrm{t}-\mathrm{t}_{5}\right)$

$\left(\mathrm{nV}_{0}+\mathrm{VCr}\left(\mathrm{t}_{5}\right)\right) /\left(\mathrm{Z}_{0} /\left(\sqrt{ }\left(1+\mathrm{n}_{\mathrm{L}}\right)\right) \sin \omega_{\mathrm{r}} 1 /\left(\sqrt{ }\left(1+\mathrm{n}_{\mathrm{L}}\right)\right)\left(\mathrm{t}-\mathrm{t}_{5}\right)\right.$

$\mathrm{i}_{\mathrm{Ls}}(\mathrm{t})=-\mathrm{i}_{\mathrm{Lr}}(\mathrm{t})$

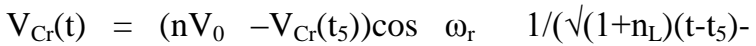

$\mathrm{Z}_{0} /\left(\sqrt{ }\left(1+\mathrm{n}_{\mathrm{L}}\right) \mathrm{I}_{\mathrm{Lm}} \sin \quad{ }_{\mathrm{r}} 1 /\left(\sqrt{ }\left(1+\mathrm{n}_{\mathrm{L}}\right)\left(\mathrm{t}-\mathrm{t}_{5}\right)-\mathrm{nV}_{0}\right.\right.$

$\Delta \mathrm{t}_{6}=(\sqrt{ }(1+\mathrm{nL})) /(\omega \mathrm{r}) \sin ^{-1}\left[\mathrm{I}_{\mathrm{Lm}} / \sqrt{ }\left[\left(-\mathrm{I}_{\mathrm{Lm}}\right)^{\wedge} 2+\right.\right.$

$\left.\left[\left(\mathrm{nV}_{0}+\mathrm{V}_{\mathrm{Cr}}(\mathrm{t} 5)\right) / \mathrm{Z}_{0} \sqrt{ }\left(1+\mathrm{n}_{\mathrm{L}}\right)\right]^{\wedge} 2\right]$

$\mathrm{i}_{\mathrm{Lr}}(\mathrm{t})=0$

$\mathrm{i}_{\mathrm{Ls}}(\mathrm{t})=0$

$\mathrm{V}_{\mathrm{Cr}}(\mathrm{t})=\mathrm{V}_{\mathrm{Cr} 0}$

$\Delta \mathrm{t}_{7}=(1-\mathrm{D}) \mathrm{Ts}-\sum \mathrm{t}_{\mathrm{k}} \quad$ where $\mathrm{k}=1$ to 6
Mode 7 [Fig.3(g): $t_{6}<t<t_{7}$ ]: In this stage, the resonant current $i_{\mathrm{Lr}}(t)$ and the current $i_{\mathrm{Ls}}(t)$ in leakage inductor $L s$ is equal to zero, and the diode $D_{2}$ is naturally turned off with ZCS. The energy stored in magnetizing inductor $L_{\mathrm{m}}$ is continuously loaded through $D_{1}$. This operating behaviour is the same as the conventional PWM flyback dc/dc converter operating at turnoff

state. The resonant current $i_{\mathrm{Lr}}(t)$, resonant voltages $V_{\mathrm{Cr}}(t)$, and the current $i_{\mathrm{Ls}}(t)$ in leakage inductor can be described as (25) - (28)

After stage 7 , the circuit operation returns to the first stage. The resonant voltage $v \mathrm{Cr}(t)$ returns to the initial value $V_{\mathrm{Cr} 0}$. Both resonant current $i \operatorname{Lr}(t)$ and $i \operatorname{Ls}(t)$ return to zero.

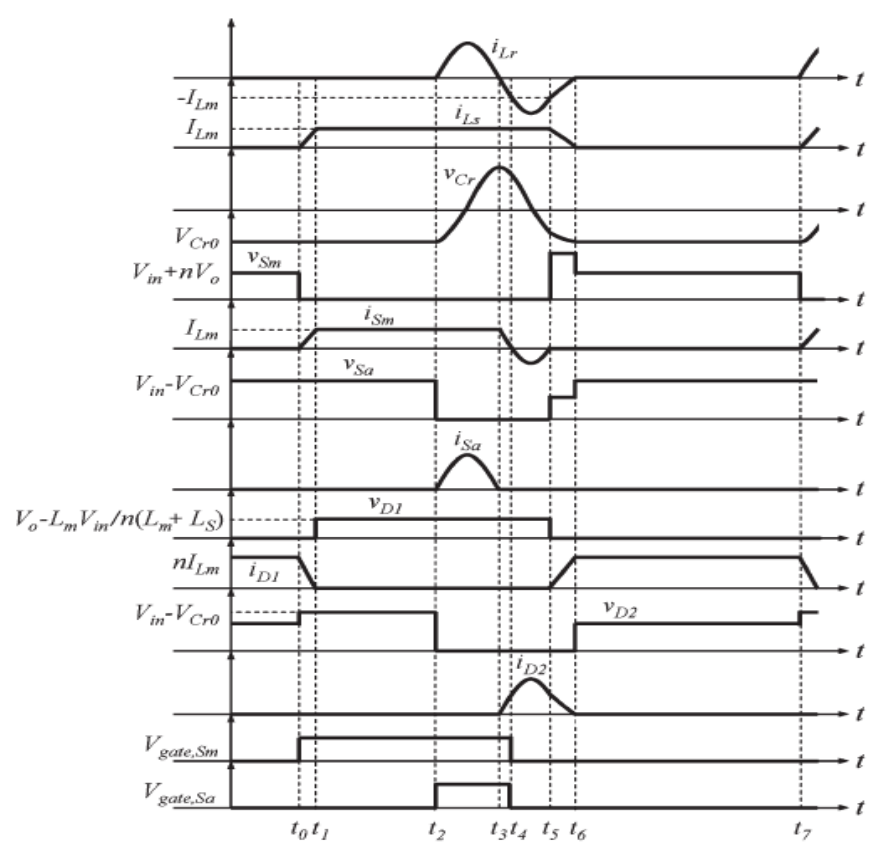

Fig. 4 Ideal waveform of ZCS-PWM flyback converter 


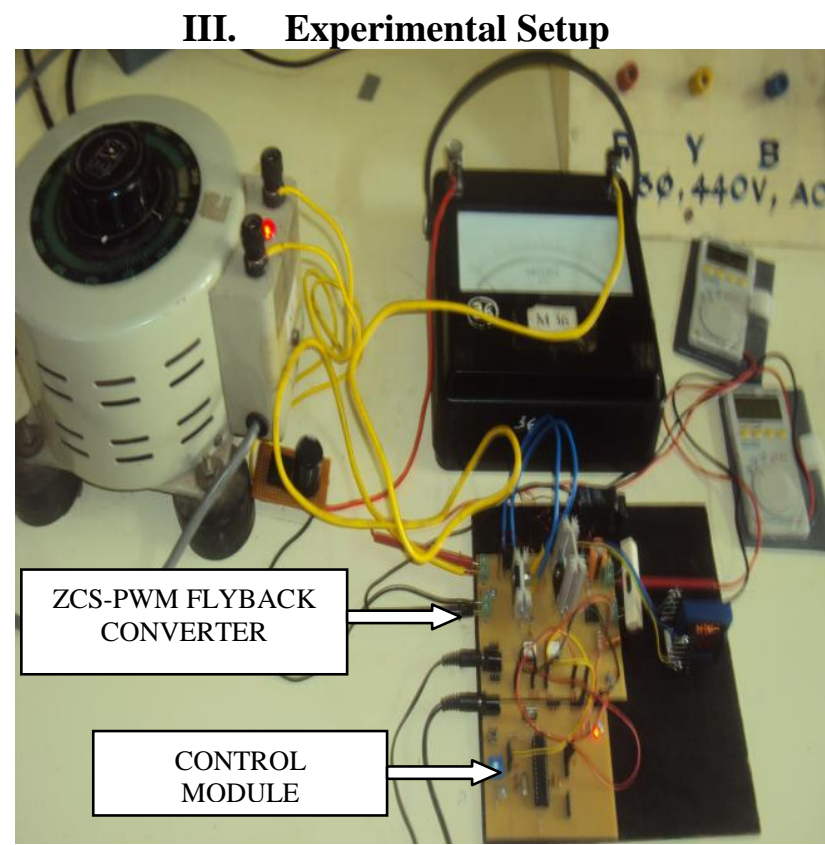

Fig. 5 Experimental setup of zcs-pwm flyback converter

Figure 5 shows the experimental setup of zcs-pwm flyback converter. It consists of an autotransformer associated with a rectifier module to provide an input voltage of $0-100 \mathrm{~V}$ dc.The control module is provided with $12 \mathrm{~V} \mathrm{dc}$ supply. A $15 \mathrm{~V} \mathrm{dc}$ supply is provided to the converter module for the optocouplers. The output voltage is measured and is obtained as $12 \mathrm{~V}$ dc. The specifications are:
1) Input Voltage $\rightarrow 100 \mathrm{~V}$ dc
2) Output Voltage $\rightarrow 12 \mathrm{~V} \mathrm{dc}$
3) Switching Frequency $\rightarrow 80 \mathrm{kHz}$

The hardware parameters are:

1)Transformer magnetizing inductor $L \mathrm{~m}: 800 \mu \mathrm{H}$

2) Transformer turns ratio $n: 3$

3) The resonant parameters: $L \mathrm{r}=20 \mu \mathrm{H}, C \mathrm{r}=16 \mathrm{nF}$.

4) Power switches and diodes: S1, $S 2$ : FGA25N120s, 1N4007 \& $1 \mathrm{~N} 5822$

5) The output capacitor: $C \mathrm{O}=470 \mu \mathrm{F}$

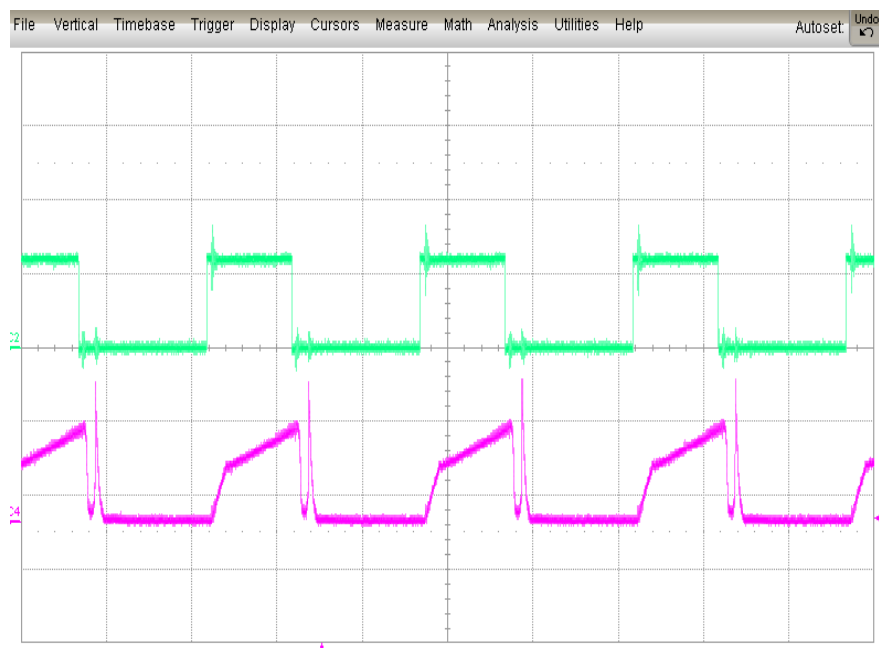

Fig. 6 Zero Current Switching of main switch Sm 


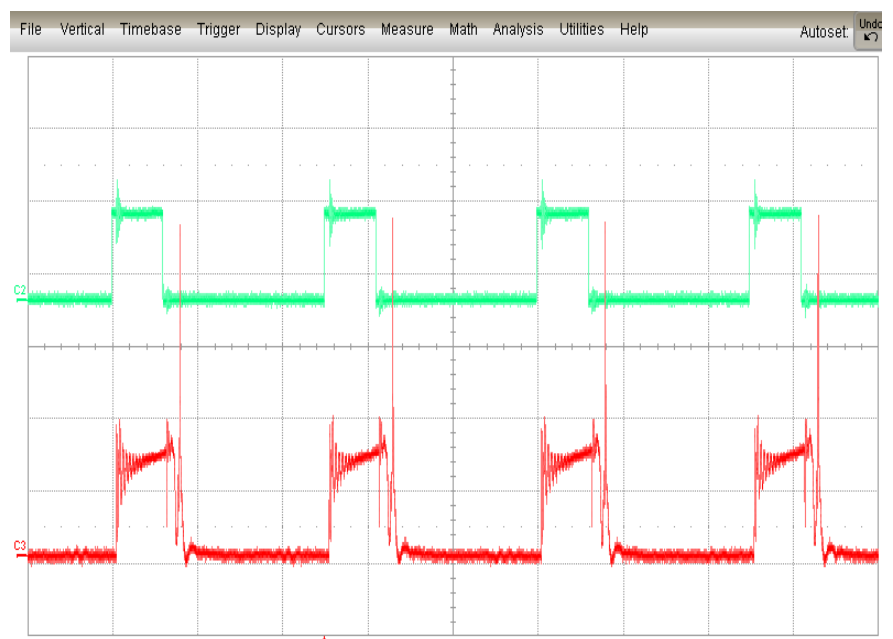

Fig. 7 Zero Current Switching of auxiliary switch Sa

The hardware results shown in Fig.6 and Fig.7 shows the achievement of zero current condition demonstrate that ZCS is achieved at constant frequency for both active switches ( $S \mathrm{~m}$ and $S \mathrm{a}$ ). It should be noted that the auxiliary diode $D 1$ and the main diode $D 2$ were also softly commutated under ZVS. Therefore switching energy losses for the zcs-pwm converter are practically zero. The main switch and diode have no additional current stress compared to the conventional converter.

\section{Conclusion}

This paper discusses about a simple and compact configuration of new ZCS-PWM flyback converter. The principle of operation and different modes of operation are analysed. Experimental results in section III shows that ZCS condition is achieved for both the switches. The proposed converter is regulated by the conventional PWM technique at constant frequency.Therefore, the ZCS-PWM flyback dc/dc converter combines the advantages of the PWM and ZCS techniques without additional current stresses compared to the conventional hard-switching method, improving converter performance and maintaining high efficiency.

\section{References}

[1] Subi S.,Indu V.," ZCS-PWM flyback converter for low voltage high current application," in Proc. Of National Conference on Technological Advancements in Power and Energy, vol.1, pp. 142-147, $4^{\text {th }}-6^{\text {th }}$ July 2013.

[2] Chien-Ming Wang, "A novel ZCS-PM flyback converter with a simple ZCS-PWM commutation cell," IEEE Trans. Ind. Electron., vol. 55, no.2,pp.749-757, Feb. 2008.

[3] Jaroslav Dudrik, Juraj Oetter," High-Frequency Soft-Switching DC-DC Converters for Voltage and Current DC Power Sources", National Conference Proceedings,vol. 4, No. 2,2007

[4] J. Y. Lee, "Single-stage AC/DC converter with input-current dead-zone zone control for wide input voltage ranges," IEEE Trans. Ind. Electron., vol. 54, no. 2, pp. 724-732, Apr. 2007.

[5] N. Kasa, T. Iida, and L. Chen, "Flyback inverter controlled by sensorless current MPPT for photovoltaic power system," IEEE Trans. Ind. Electron, vol. 52, no. 4, pp. 1145-1152, Aug. 2005.

[6] C. M. Wang, "Novel zero-voltage-transition PWM DC/DC converters," IEEE Trans. Ind. Electron., vol. 53, no. 1, pp. 254-262, Feb. 2006.

[7] C. M. Wang, "New family of zero-current-switching PWM converters using a new zero-current-switching PWMauxiliary circuit," IEEE Trans. Ind. Electron., vol. 53, no. 3, pp. 768-777, Jun. 2006

[8] B. R. Lin and F. Y. Hsieh, "Soft-switching zeta-flyback converter with a buck-boost type of active clamp," IEEE Trans. Ind. Electron., vol. 54, no. 5, pp. 2813-2822, Oct. 2007.

[9] N. P. Papanikolaou and E. C. Tatakis, "Active voltage clamp in flyback converters operating in CCM mode under wide load variation," IEEE Trans.Ind. Electron., vol. 51, no. 3, pp. 632-640, Jun. 2004.

[10] Y. S. Lee, Y. Q. Hu, and K. W. Siu, "Single-switch electronic ballast with near-unity power factor and soft-switching characteristic," IEEE Trans. Ind. Electron., vol. 48, no. 6, pp. 1188-1195, Dec. 2001.

[9] H. Chung, S. Y. R. Hui, and W. H. Wang, "An isolated ZVS/ZCS flyback converter using the leakage inductance of the coupled inductor," IEEE Trans. Ind. Electron., vol. 45, no. 4, pp. 679-682, Aug. 1998. 